\title{
DEFENDING THE TRUTH AND COUNTER INFORMATION WARFARE IN EUROPE
}

\author{
Silviu NATE *, Aurelian RAȚIU** \\ *"Lucian Blaga" University of Sibiu, Romania \\ "Nicolae Bălcescu" Land Forces Academy of Sibiu, Romania \\ silviu.nate@ulbsibiu.ro, aurelian_ratiu@yahoo.com
}

\begin{abstract}
Information warfare has gained new valences, although some states have historical roots in developing subversive and manipulative tactics; the action pattern is supported today by the use of new information propagation vectors, access to new technologies, and a mix of themes with political, economic, military, cultural and social collective interest. The aim of the propaganda is that the aggressor demoralizes and minimizes the trust of citizens in domestic institutions and policies. Hypotheses and work themes are combined with false news, counterfeit media, capable of creating ambiguity. On such a media of open sources, non-kinetic threats and elements of the hybrid war manifest themselves in the information space and create the ambiguity much hoped to diminish the establishment that reflects the aggressor's opposition. The study presents relevant cases and recommendations for members of the Euro-Atlantic community related to the management of Russian information actions.
\end{abstract}

\section{Keywords: information warfare, kinetic threats, propaganda, defense, Russia}

\section{Introduction}

Information is a key substitute of manipulation. Analysis of conflicts in the proximity of Romania submits that North Atlantic Treaty Organization and the European Union should adjust to the new actuality in which the dominance of communication strategies, in relation to the defense command, is getting more importance. Regional security instability was often associated with Russia's involvement in the region. Thus, in the current information environment that is constantly evolving, influence can certainly be achieved by manipulation techniques that disturbs not only the economic markets, or national policies, but also effects discernments, feelings and behaviors of society. Although information itself has an extraordinary value, the way it is offered transforms it into a decisive tactical instrument.

Analysis of the public's structure and profile is critical to operational success. The public has a significant importance for operational success. Although the campaign of information aggression has managed to influence its audiences, it also has a certain degree of counter-productivity, because it has radicalized the local public that belong to NATO countries, the EU and the US.

Information operations are often an integrated part of hybrid warfare's ambitions and tactics. Frank Hoffman labeled "hybrid war" as a "blend of the lethality of state conflict with the fanatical and protracted fervor of irregular war"[1]. Usually, the broader concept of information warfare is reflected into refined information operations that associate small scale 
traditional and special media campaigns; aggressive cyber-attacks; and psychological maneuvers that use social media and traditional information vectors to influence public perceptions and opinions[2].

\section{Towards a postmodern propaganda}

Since early 2000, Russia's National Security Concept has highlighted an increasing risk to national security in the field of information. Russia's 2007 Foreign Policy Review recommends to multiply the number of media diffusion abroad of news agencies in the Russian state and expanding their offices in other countries.

The Russian Federation conceptualized in 2009 its national security strategy, which was linked with the former Foreign Policy Review (2007) and contributed relatively, to enhance later the operations in Eastern Ukraine. The Russian State Security Strategy contains a section dedicated to cultural issues, emphasizing a collective area of information incorporating Russia, the Commonwealth of Independent States and adjacent countries.

This common sphere of information for the Russian communities is preserved and augmented by the application of the policy of compatriots, which is seen as a method to exert soft power over the neighboring regions. It is obvious that the policy of compatriots operates as an effective instrument for geopolitical impact, serving Russia to achieve particular objectives abroad.

The Russian doctrine called Conceptual Views Regarding the Activities of the Armed Forces of the Russian Federation in the Information Space (2011) specifically refers to war when it calls to information operations, as a totally different contrast by the Euro-Atlantic societies' approach, seen as a public and open campaign tool. The Russian doctrine, labels information war as a: "confrontation between two or more states in the information space to damage the information systems, processes and resources, which are of critical importance, and other structures, to undermine the political, economic and social system, and effect massive brainwashing of the population for destabilizing the society and the state, and forcing the state to make decisions in the interests of the confronting party"'[3].

Russian intrusion of western nations' public networks and social media would consist, under this conceptual approach, a declaration of war on the pattern of softpower techniques and tools.

According to American thinker Joseph Nye, "Soft power is the ability to affect others to obtain the outcomes one wants through attraction rather than coercion or payment. A country's soft power rests on its resources of culture, values, and policies. A smart power strategy combines hard and soft power resources"[4]. Public diplomacy becomes a decisive instrument which completes smart power, but to become sustainable it should embrace democratic values, to be open to self-criticism, and be fully credible or provable.

Propaganda is emotionally charged and based on aggressor's interest, it exploits public persuasion to cultivate the collective mindset to the advantage of the aggressor's intentions and goals; while public diplomacy, advance a visible public ideas exchange which is less unscrupulous than propaganda. Involved participants are more proactive, it is based on a coherent feedback between public institutions and societal actors.

Russian information warfare is not able to achieve results on the long run in Europe; the competition to win hearts and minds in western countries is undermined by her own political weakness, lack of demonstrative facts and actions. Russia's manipulation techniques are known for a long time, but diversification and concentration of tactics are growing significantly. Late, other countries began to comprehend that info-fabrication is a real danger to the Euro-Atlantic space. Frequently, Kremlin uses disinformation in 
the West to contaminate the medias, intensify societal segregation, and deteriorate the collective confidence in the democratic system. Those engagements encourage, on a false pattern of information operations, the decline in trust in national institutions and western alliances. Supporting this phenomenon, Walter Lippmann states that propaganda is impossible without censorship, because censorship is allowed a barrier between the company and the event, thus preventing individuals from forming their own version of the events.

The magnitude of the fake news promoted by Russia, and the expose of their prominent display, would narrow its intangible capital to European public arena. Disinformation campaigns erodes over time as they discover hidden or misleading information. It remains to be seen whether Russia has won a long-term enemy from Western Countries.

The examination of the Russian storyline generates the assumption that the Russian broadcasting exhaustively promoted a sense of worry and apprehension in the Russian ethnic population of Ukraine, but also inside the non-Ukrainian groups. Throughout the first stage of the Russian "intervention" in Crimea, the whole Ukrainian population was "stimulated" to get a sense of uncertainty regarding its economic potential for development and security. The Kremlin's rhetoric concluded that a rapprochement of Ukraine to the European Union values and market would represent a more withdrawn economic cooperation of Russia, and it was frequently insinuated that the European Union efforts to approach Ukraine into a native business instead of planning to help advance the economy of Ukraine.

When analyzing the stories of Russian propaganda, it is critical to keep in mind that this phenomenon began before 2014 . Samuel Huntington's civilization theory has become very useful to the Russian thinkers as an option to route an imaginary cultural frontier between the Orthodox world and the western countries and civilizations. The concept of clashing civilizations has frequently emerged in the rhetoric of the Russian leaders and thinkers, and other counterparts between 2004 and 2007. The culmination is President Putin's speech, issued at the Munich Security Conference in 2007, where he condemned the US for continuing to preserve a unipolar order, therefore orthodox civilization "would seem incomplete" without Ukraine.

Kremlin's communication strategy for Poland is focused on the promotion of the message that the western countries undermine national values. A similar rhetoric is found in Eastern Europe and The Baltic countries which are pictured for their own citizens as failures - affected negative vulnerabilities and threats like poverty, chaos, corruption, expatriation; led by evil elite of Westerns with fascist sympathy.

The Russian information warfare targets also Scandinavian states. Finland is threatened with the Third World War by Russia, and Denmark is intimidated that will become a nuclear target if it chooses to joins the NATO missile defense program[5].

\section{Informational aggression perceived by other states}

In the Annual Risk Assessment published by the Danish Defence Intelligence, the document highlights that "Russia uses a wide range of instruments, including information campaigns through Russian state-controlled media targeting Western audiences; dissemination of partially false and biased information through Russian think tanks, research institutes, official news outlets, bloggers, and commentators who pretend to be independent"[6].

Danish Minister of Defence Claus Hjort Frederiksen expressed, in April 2017, his concerns regarding the Russian hacking of Danish military email accounts. "This is part of a continuing war from the Russian side in this field, where we are seeing a 
very aggressive Russia"[7]. Submitting the general vision and hypothesis of the Russian Doctrine, it becomes obvious that Russia is at war with the West; is it quite complicated to understand when the war started, but is predictable to assume that it never ends because it already has become a part of the western mainstream media and politics.

Kremlin's propaganda overthrows and removes any condemnation of Russia's own actions. Undesirable comments about Russia are described as being imaginary or bigoted, the consequence of western ego and preconceptions. In a CEPA research paper, Ben Nimmo, NATO intelligence expert and former NATO spokesman, exemplifies these methods as critical rejection, distortion of facts, distraction from the principal problem, and public astonishment[8]. Russian information warfare uses challenging offensive tools, with a long history.

In the Fog of Falsehood study, the Finnish Institute for International Affairs identifies the persistence of the concept of reflexive control[9]. We discover a new type of war in which the aggression does not exterminate the adversary by acting externally, but it can drive to selfdestruction. Reflex control practitioners try to find a fragile connection in the enemy's filter - experience, perceptions, beliefs, awareness, are the prerequisites for collective judgements.

Although the instruments seem to be connected to the traditional pattern, the tactics and vectors used have changed. Russia's new propaganda symbiosis is not centered anymore to promote communism in sight or on the glory of the values promoted during the Cold War. Instead of these highly articulated ideologies, we find a postmodernist repudiation of the entire liberal view of European democracies. Democracy is not suitable for Russia; it is rather a fiction; elites are corrupted and unreasonable. Russia doesn't use an articulated meaning, and storylines frequently contradict each other. The new Russian's strategy of communication is aimed to encourage extremist and radical political parties' ascension in Europe, as well as to any public movement in contradiction of the extremists' competitors.

While reporting on events in Ukraine, state broadcasting journalists have systematically distorted recorded audiovisual material to deliver media products that fit into the Russian's propaganda agenda and dominant storyline. They manipulated photography from wars in Chechnya, Kosovo and Syria, and presented them as coming from the East of Ukraine and proved to be particularly effective in social networks.

Another falsification trend was filming the same person in different roles and situations. This person played a multiple role of participant in Anti-Maidan, Resident in Kiev, the Crimean activist, and the soldier's mother[10].

As usually seen on Baltic states and Ukraine, Kremlin efforts its propaganda to stimulate a message of unification and attracts the support of compatriots with dominant pro-unionist views and beliefs. The history of suffering and melancholy of Soviet grandeur are urged to intensify the feeling of dissatisfaction of Russian ethnics in the Baltic states. Lithuania seems to be a proper ground for the propaganda that targets cultural feelings. Russian energy enterprises advocate for the national cause and interest in Germany.

The labeling as Russian propaganda of critical views about Romania's current military capabilities, or the strategic or tactical place occupied by Romania in NATO's plans, frizzes the security (Securitate) paranoia of the past which is totally futile. Certain television stations have been encouraged into the position taken by institutions not in line with the imperatives of "anti-corruption". On the informational level, it seems that Russia prefers to invest in the troll-like information war, rather than in an open propaganda war 
in Romania. Trolling at this level may mean not only the dissemination of visions or information but also the use of discursive tactics to intimidate, confuse, demobilize target audience, and challenge, etc.

The large number of media available create a suitable field for generating confusion in the space of targeted population, and usually becomes difficult to distinguish between imaginary stories and real facts. Instead of searching for veracity, the general public prefers to stay in the comfort zone and don't care about it too much. A research directed by the Open Estonia Foundation illustrates that compatriots who live in Estonia and watch media from Estonia and the Kremlin end up believing no one and aren't able in fact to formulate an opinion.

Today's Russian propaganda is intelligent, technically capable and cynical without facts. Postmodern propaganda is very emotional; it brings together the melancholy of Soviet glory and the public media showbiz.

\section{Non-kinetic threats}

Kinetic war is intense and influential, but restricted in its efficiency, while non-kinetic war is extensively less violent, but more successful. Using a mixture of cyber and IT warfare, economic war, its determination is to proliferate ambiguity or weariness at the level of aggressed nation.

A list of elements in the non-kinetic range would comprise the following:

- $\quad$ the open and hidden propaganda;

- $\quad$ placement of funds in media, thinktanks, political parties or academic institutions;

- $\quad$ targeting corruption to gain access at decision-making panel;

- use organized crime networks to discourage opponents, raise funds outside groups, and demoralize target groups;

- $\quad$ exploiting identity and symbolism connected to collective beliefs.

The usage of economic weapons develops a proper ground to make corruption more attractive and more effective for the aggressor. A special benefit for Russia is that the non-kinetic war achieves comparable goals as a conventional warfare.

Writing for the NATO Review, Peter Pindjak, a Slovak diplomat, emphasizes NATO's effort on a rapid military response with 3 prospective vulnerabilities. Firstly, Member States may find it problematic to get a consensus on the origin of a nonkinetic threat, generating an obstacle to take common attitude. Secondly, to counteract asymmetrical threats, the only hard power is inappropriate (...) in the end, a disaster based only on the military intervention will not be convincing. As for asymmetric threats, NATO cannot refresh its massive retaliation strategy or rely solely on an action path[11].

It is hard to project and identify a maximum level when the propaganda or the military intimidation become the prologue to a demonstration of muscles or a capability experiment. This new kind of "information deterrence" represents an annoying and harassing mind game. If the non-kinetic war represents a common threat, a joint answer cannot be easily developed in the West. There are no military-civil ties that underlie a culture of security - similarities, behaviors and common practices permit societies to address a mutual danger.

\section{Response paths}

Today's information environment is deeply fractured. Cross-border media and internet create parallel patterns for getting information and develop attitudes/reactions. We present several collected recommendations to handle those threats at tactical and strategic level:

a. Developing a European analysis, target audience, media, and social network analysis centers. At a smaller community level, it is easier to identify and analyze what security needs are and what are the targets for propaganda. This makes it easier 
to propose countermeasures for various social segments.

b. Developing a strong regulatory body, an alternative where internal public media has weak standards. An ethics code for journalists and monitoring programs developed by civil society's advised groups would alert and limit the spread of hate speech and noxious info-fabricated products.

c. Creating an inter-departmental hub for non-kinetic intelligence analysis and response, able to deal with soft-power tools and strategies, capable of deciphering propaganda and false storylines. Consequently, the "need to share" principle is needed more than ever and would contribute to expose malicious information tactics and help the policy-makers to shape coherent counterstrategies.

d. Block streams and webpages that promote false manipulative audio-video content and fake news. Exposing reality and directing real content to end-users. This can help to increase civilian awareness and grow the level of security culture. Also, those tactics, which are similar with the aggressor's techniques, but positively oriented, would be aimed to avoid radicalization.

e. A 2016 Stratcom NATO's report, the Hybrid Battle Instrument, advises governments to "increase critical public thinking and media literacy". The information society is exposed to a totally new phenomenon and technologies; it should put their efforts in media and internet education.

f. Programs to avoid the proliferation of hate speech, demonizing LGBT people, incitement to violence, on local media channels.

\section{Conclusions}

Subversive action in a state's policy is part of Russia's tactical arsenal and military historical heritage. Russia's involvement has often led to the undermining of citizens' trust towards their own institutions and leaders, the discrediting of their political rivals or threatened to interrupt mutual relations. The same reaction we find today when Russia threatens Romania with interruption of all kinds of relations because Romania supports military exercises and the deployment of NATO military forces in the Black Sea.

Russia uses thematic frameworks that refer to Soviet glory, the desire to reunite the exSoviet states under the one dome, the theme of legitimacy to recover a lost cultural patrimony with the help of compatriots, the theme of the failed and immoral Western, Russia's alternative to a civilization in collapse, etc. Of all this arsenal, in fact superficial, more as an act of masquerade, the general public does not make a deep correlation with the political and economic landscape of Russia. These lying and distorted themes, accompanied by the lack of authentic democracy in Russia, and its monochrome economic landscape make it a surrogate in international relations, an artificial actor who becomes more dangerous because it is hiding in the shadow of deceptive interests and nontransparency. This trick of circus accentuates the gap between Russia and democratic states, and Russian society is invited to consume the mirage of some excessive theories of self-exclusion.

Russia acknowledges the economic needs and interests of European Union members and speculates their difficulty in obtaining consensus on common issues. Europe survived and stood up after a tumultuous history, but the need to strengthen confidence with eastern Europe still has historical grounds. All these are topics and working hypotheses for Russia in an attempt to question the Euro-Atlantic cohesion. 


\section{References}

[1] Frank G. Hoffman, Conflict in the 21st Century: The Rise of Hybrid Wars, VA: Potomac Institute for Policy Studies, Arlington, 2007, p. 38.

[2] Military Balance 2015, The Annual Assessment of Global Military Capabilities and Defence Economics, Chapter 1, Part III: Hybrid warfare: challenge and response, International Institute for Strategic Studies, p.97, 2015.

[3] Conceptual Views Regarding the Activities of the Armed Forces of the Russian Federation in the Information Space (2011), available at https://ccdcoe.org/strategies/Russian_Federation_unofficial translation.pdf.

[4] Joseph S. Nye, Jr., Public Diplomacy and Soft Power, The Annals of the American Academy of Political and Social Science, Vol. 616, Public Diplomacy in a Changing World, p. 94, Mar., 2008.

[5] Edward Lucas and Peter Pomeranzev, Winning the Information War Techniques and Counter-strategies to Russian Propaganda in Central and Eastern Europe, Center for European Policy Analysis, 2016, https://cepa.ecms.pl/files/?id plik=2706.

[6] Intelligence Risk Assessment 2016, An Assessment of Developments Abroad Impacting on Danish Security, Copenhagen, Danish Defence Intelligence Service, p. 12, 2016, https://fe-

ddis.dk/SiteCollectionDocuments/FE/EfterretningsmaessigeRisikovurderinger/Risikovu rdering2016 EnglishVersion.pdf.

[7] https://www.nytimes.com/2017/04/24/world/europe/russia-denmark-hackingcyberattack-defense-ministry.html? $\mathrm{r}=1$.

[8] http://cepa.org/files/?id plik=1896.

[9] Katri Pynnöniemi \& András Rácz (eds.), Fog of Falsehood Russian Strategy of Deception and the Conflict in Ukraine, Helsinki, The Finnish Institute of International Affairs, Grano Oy, p.33, 2016, http://www.fiia.fi/assets/publications/FIIAReport45 FogOfFalsehood.pdf.

[10] http://bit.lyluSMe01.

[11] Peter Pindják, Deterring hybrid warfare: a chance for NATO and the EU to work together? NATO Review, 2014, http://www.nato.int/docu/review/2014/also-in2014/Deterring-hybrid-warfare/EN/index.htm. 